\title{
EXPRESSWAY LONGITUDINAL SLOPE DESIGN CONSIDERING VEHICLE CARBON EMISSION IN CHINA
}

\author{
JIA, X. L. ${ }^{*}-$ PENG, J. - LIU, X. L. \\ ${ }^{I}$ School of Highway, Chang'an University \\ Middle-section of Nan'er Huan Road, Xi'an 710064, P.R. China \\ (phone: +86-29-8-233-4864) \\ *Corresponding author \\ e-mail: jxl0126@sina.com \\ (Received 28 $8^{\text {th }}$ Oct 2016; accepted 28 ${ }^{\text {th }}$ Feb 2017)
}

\begin{abstract}
In China's coal producing areas, carbon emission has a significant impact on the environment, so more attention has focused on the development of heavy vehicles and expressway designation. However, no national criterion based on carbon emission for overload expressway designation exists. In this paper, we propose building a connection between longitudinal segment design parameters and carbon emission, using diesel fuel consumption data and a nonlinear iterative regression method. A carbon emission relational model was built, showing the connection between carbon emission and gradient, slope length, and initial speed. The carbon emission database of expressway longitudinal slope was established by existing model. Based on the actual design data, the sensitivity analysis of gradient and slope length in the established model is carried out. As a result, the influence of gradient on the cumulative carbon emissions is obvious and higher sensitivity, reaching 4.550 . The carbon emissions will increase significantly after the longitudinal slope is greater than 3\%, highway longitudinal slope should be less than 3\%, and the road longitudinal slope length should be limited.
\end{abstract}

Keywords: carbon emissions model; heavy vehicle; longitudinal gradient; slope length; multiple nonlinear iteration regression; diesel fuel consumption

\section{Introduction}

The rapid development of China's expressway network is accelerating the economy, but carbon emission from vehicles has led to deterioration associated with global warming (Yuan et al., 2016; Morrow et al., 2010; Brown et al., 2009). In China's coal-producing areas, overload expressways are major transportation corridors. On the Hohhot-Jining and Chengde-Tangshan expressways, heavy vehicle volumes constitute more than $40 \%$ of the total. When driving on sloped segments, vehicles consume more fuel to climb, emitting more greenhouse gases. Therefore, vehicles on expressway longitudinal sections produce strong carbon emissions.

Nonetheless, diesel fuel used by heavy vehicles is a type of environmentally friendly energy (Huang et al., 2010; Chen et al., 2007), but a large gap exists regarding fuel quality and vehicle performance relative to western countries (Durbin et al., 2007). These two characteristics have greatly decreased the environmental performance of diesel. Thus, carbon emission should be considered in expressway designation, especially along longitudinal sections of overload expressways. However, there is a lack of suitable criteria in China for such consideration. To guide such development, this paper describes efforts to relate longitudinal roadway segment design parameters and carbon emissions 
derived from diesel fuel consumption data using an iterative nonlinear multiple regression method.

For driving on expressways, many factors that affect carbon emission exist, so it is difficult to systematically quantify this emission. However, after years of research, vehicle carbon emission models with actual road conditions have gradually improved and become more effective.

\section{CHANGER Model}

This model was implemented by the International Road Federation based on road life cycle theory. Because it has been developed for a long period, and the factors taken into account were not systematic, the model has two defects (De Cauwer et al., 2015; Imhof et al., 1996; Jiao et al., 2014; Rogers et al., 2009). The calculation cycle is not complete, and the full life cycle is not achieved, so accuracy of calculation result is poor. The material information is inconsistent with the actual situation in China, and the applicability is very limited.

\section{ASPECT Model}

ASPECT was developed by the British Transport Research Institute. It takes the complete and detailed life cycle into consideration, and analyzes engineering technology on low-carbon roads. Also, it provides a carbon reduction factor for recycled road materials, so this model has favorable applicability to actual road conditions (Kang and Min, 2016; Oh and Cha, 2015; Ortenzi et al., 2008).

However, the model's material information is inconsistent with the current situation in China, causing a large discrepancy in the carbon emission conversion factor. It is therefore not suitable for use in the country.

\section{MOBILE Model}

This model was developed by United States Environmental Protection Agency (EPA), based on Federal Test Procedure (FTP) driving conditions (Joumard et al., 2000; Feng et al., 2013). The model tests the vehicle carbon emission level for obtaining a basic carbon emission factor under standard conditions. Then, that factor is corrected by other influential factors to obtain the actual carbon emission (Liu et al., 2011; Shah and Zeeshan, 2016). However, the model has two shortcomings:

1. FTP-75 takes average speed as a main parameter in actual driving conditions, but it is very different from actual operation. Furthermore, because of the limitations of laboratory conditions, simulated speed and acceleration are lower than those in actual road conditions, leading to poor accuracy of vehicle carbon emission quantization.

2. The model is based on vehicle operating conditions in the United States and FTP driving conditions. The carbon-emission empirical formula is built with simulated 
data in the laboratory. Thus, this model is not suitable to the situation in other countries, and the accuracy of simulated results is not guaranteed.

\section{COPERTIV Model}

This model was developed by the Europe Environment Agency based on the Economic Commission for Europe-15 + Extra Urban Driving Cycle (ECE15+EUDC) test driving conditions, which takes average speed as the main operating factor (Qin et al., 2009). The first step in this model is to transform regional energy consumption to basic carbon emission, and it then obtains the assumed mileage and speed using other data. The last step is to obtain the actual carbon emission through mutual correction (Frey et al., 2008; Trainer, 2010; Peng et al., 2015). Again, however, there are two limitations that have obstructed its development.

1. According to related findings, the simulated emission result based on ECE15+EUDC is about $20 \%$ lower than actual.

2. The test object of ECE15+EUDC driving conditions is a light vehicle, and motorcade information is not complete. Thus, the simulation object of COPERTIV Model is limited.

\section{IVE Model}

This model was developed by the International Institute for Sustainable Development and the University of California (Yafune et al., 2005; Lai et al., 2015). The vehicle specific power (VSP) output is used to represent actual vehicle carbon emission, and other influences are considered for correcting that emission.

The advantage of IVE is that it can explain the actual carbon emission better, so the forecast result has higher accuracy. However, because the data used by this model comes from the MOBILE detection database, it is affected by the operating condition, so the simulated result is not accurate.

\section{MOVES Model}

This model was developed by the EPA, the driving condition is represented by a combination of VSP and instantaneous speed, and instantaneous acceleration is also considered in the calculation of vehicle carbon emission (Rakha et al., 2004). Accuracy of the forecast model improves at large scale, and the simulation condition is more advanced and more realistic (Shah et al., 2004). This leads to a more comprehensive vehicle carbon emission calculation.

MOVES simulates macro, meso and micro aspects, and is compatible with each individual country factors. Therefore, it is recognized by scholars in various countries and is authoritative. 


\section{Materials and Methods}

\section{Carbon Emissions Field Experiments}

Road Section and Dominant Vehicle Type

Inner Mongolia and Hebei Province are the major coal-producing areas in China. From statistical data of the National Bureau of Statistics, coal production in the two areas accounted for $19.2 \%$ of total national production in 2014. In Inner Mongolia, the main coal production is around the cities of Erdos, Hohhot and Baotou, so highway transportation relies on the Hohhot-Jining expressway. In Hebei Province, the principal coal production is from Tangshan, so the Chengde-Tangshan expressway is vital. In our study, diesel consumption data were used to calculate carbon emission in actual road tests.

To determine the dominant vehicle type, we obtained pass records of the Mengjijie toll gate on the Hohhot-Jining expressway from 7 a.m. on 7 May 2013 to 7 a.m. on 8 September 2013, and of the Liuzhangzi toll gate on the Chengde-Tangshan expressway from 7 a.m. on 6 March 2014 to 7 a.m. on 2 July 2013. According to the data collected, the proportion of each vehicle type is shown in Figure 1.
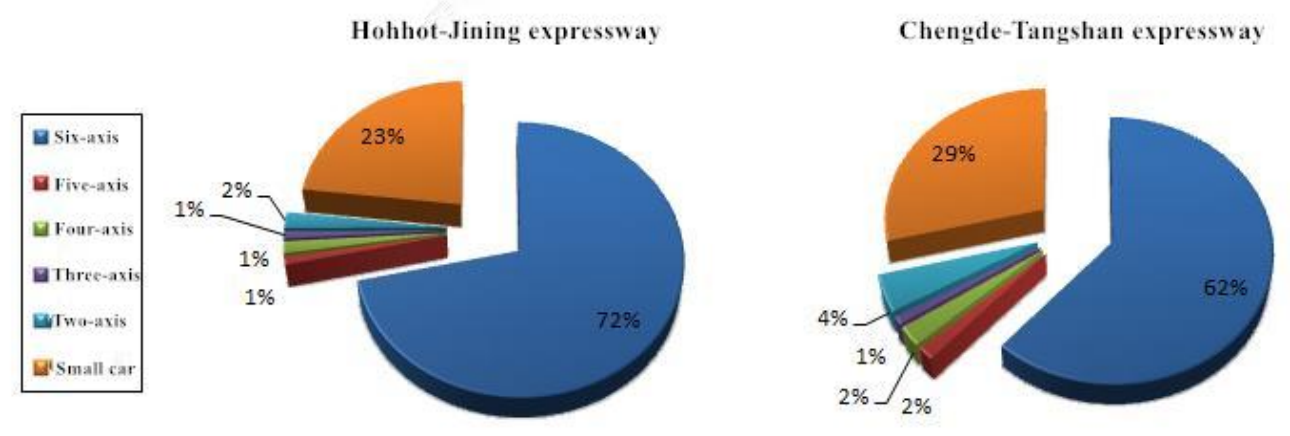

Figure 1. Vehicle type proportions

Figure 1 shows that six-axis vehicles are widespread on the test road sections. To determine the specific vehicle type, the manufacturer and actual load of such vehicles were counted. Based on the information that has been collected, in combination with the actual situation in which heavy trucks tend to be overloaded in China, the 50-t load weight, six-axis Auman heavy-duty truck was chosen as the dominant vehicle type. Moreover, this type represents the transportation development trend in the country.

\section{Field Experiments}

We used the fuel consumption instrument (of type Shenzhou JDSZ-EP-1-1) to monitor real-time fuel consumption of the test vehicle, which was chosen based on the standard mentioned in the previous section (the Auman truck, type BJ4253SMFJB-S7). This instrument is shown in Figure 2. 


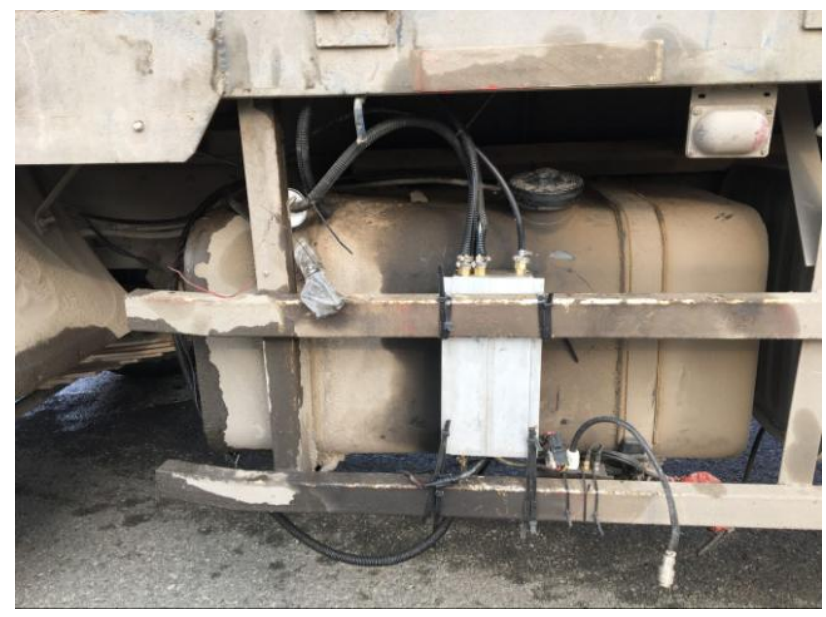

Figure 2. Fuel consumption instrument

A total of 151 sets of data were obtained. On each slope segment, the parameters of gradient (i), slope length (L), initial speed (V0), operating speed (V85), diesel consumption (DC), and carbon emission (CE) (calculated by IPCC method above) of the test vehicle were counted and calculated (National Bureau of Statistics in People's Republic of China, 2014 ). Part of the data are listed in Table 1.

Table 1. Part of data collected and calculated

\begin{tabular}{|c|c|c|c|c|c|c|}
\hline No. & $\begin{array}{c}i \\
(\%)\end{array}$ & $\begin{array}{c}L \\
(\mathbf{k m})\end{array}$ & $\begin{array}{c}V_{0} \\
(\mathbf{k m} / \mathbf{h})\end{array}$ & $\begin{array}{c}V_{85} \\
(\mathrm{~km} / \mathrm{h})\end{array}$ & $\begin{array}{c}D C \\
(l)\end{array}$ & $\begin{array}{l}C E \\
(\mathrm{~kg})\end{array}$ \\
\hline 1 & 1.04 & 0.416 & 70 & 67 & 0.14 & 0.38 \\
\hline 2 & -0.40 & 0.669 & 73 & 81 & 0.17 & 0.44 \\
\hline 3 & -0.50 & 0.232 & 75 & 78 & 0.08 & 0.21 \\
\hline 4 & -0.60 & 2.876 & 78 & 77 & 0.51 & 1.35 \\
\hline 5 & -1.92 & 0.214 & 77 & 84 & 0.07 & 0.19 \\
\hline 6 & -0.20 & 0.577 & 73 & 79 & 0.16 & 0.42 \\
\hline$\ldots$ & $\ldots$ & $\ldots$ & $\ldots$ & $\ldots$ & $\ldots$ & $\ldots$ \\
\hline 151 & -0.58 & 1.474 & 73 & 90 & 0.29 & 0.76 \\
\hline
\end{tabular}

Association of Carbon Emissions and Expressway Longitudinal Slope

We used a multiple nonlinear regression model to analyze the relationship between longitudinal geometric elements and CE. The first step was to separately build the function of $\mathrm{CE}$ with $\mathrm{i}, \mathrm{L}$, and $\mathrm{V} 0$. Then, multiple nonlinear iteration regression was used to study the function of the comprehensive relationship.

To analyze the relationship between carbon emission of unit length (CE0) and i, linear, quadratic and cubic equations were used separately for fitting. The fitting graph is shown in Figure 3. 


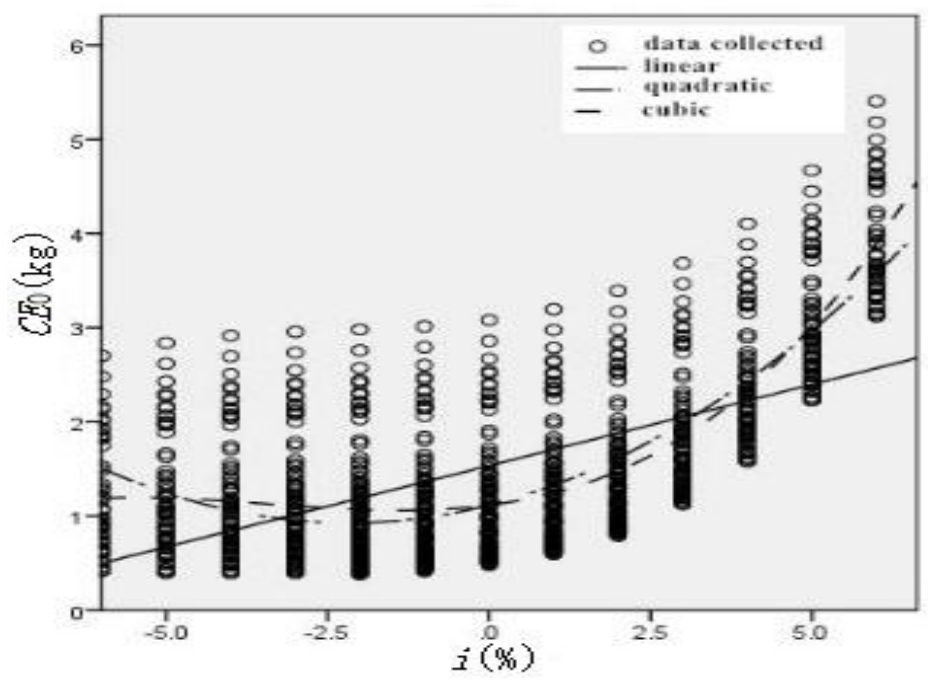

Figure 3. Fitting graph of $i$ and $C E O$

The values of AIC and BIC in Figure 3 reveal that the accuracy of the cubic equation model is greater. From the cubic equation curve fit, $\mathrm{R} 2=0.857$, the value of $\mathrm{F}$ is largest. This demonstrates the superior result of the cubic equation curve fit, so that equation was used to represent the relationship between CE0 and i, shown by Equation (1):

$$
f_{1}(i)=1.111+0.087 i+0.04 i^{2}+0.004 i^{3}
$$

To analyze the relationship between $\mathrm{CE} 0$ and L, logarithmic, quadratic, cubic, composite and power equations were used separately for fitting. The fitting graph is shown in Figure 4.

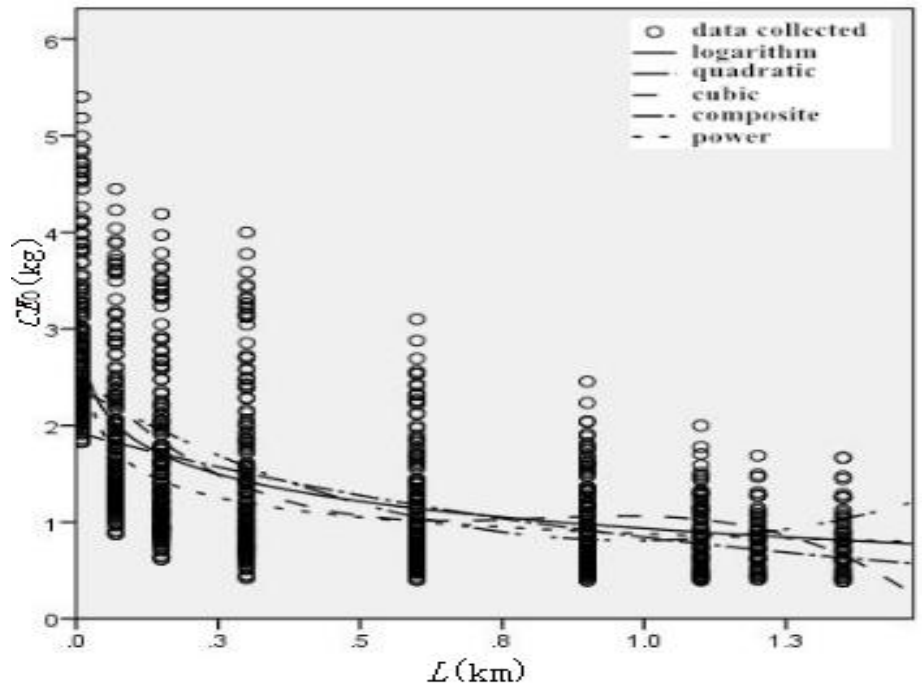

Figure 4. Fitting graph of $L$ and $C E O$ 
The equation was used to represent the relationship between CE0 and L, shown by Equation (2):

$$
f_{2}(L)=0.881-L^{-0.256}
$$

To analyze the relationship between CE0 $(\mathrm{kg})$ and V0, linear, quadratic and cubic equations were used separately for fitting. The fitting graph is shown in Figure 5.

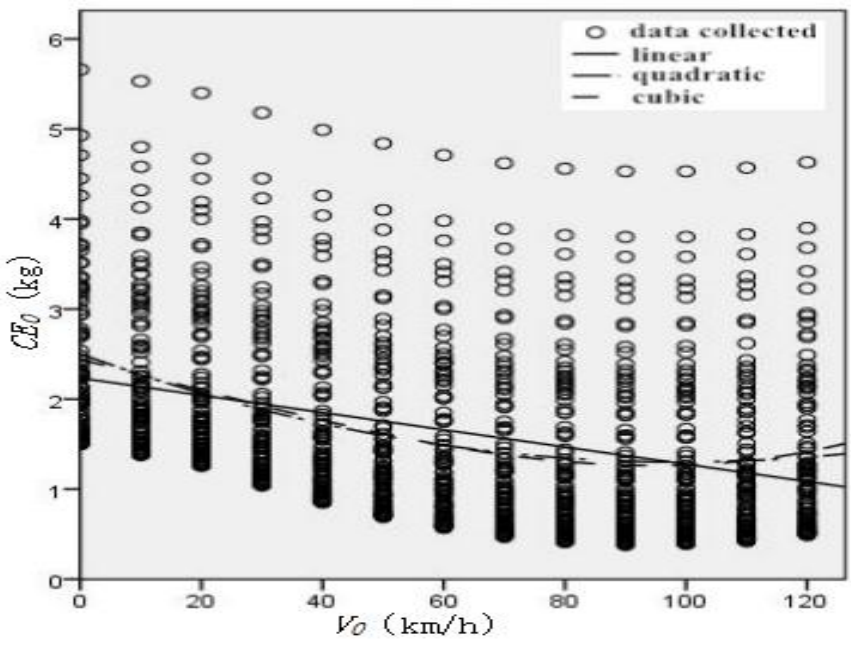

Figure 5. Fitting graph of $V O$ and $C E O$

The equation was used to represent the relationship between CE0 and V0, shown by Equation (3):

$$
f_{3}\left(V_{\mathrm{o}}\right)=1.608-0.14 V_{\mathrm{o}}+0.00015 \mathrm{~N}_{\mathrm{o}}^{2}
$$

Based on the simple regression models , using i, i2, i3, L B2, V0, V02 as independent variables and $\mathrm{CE}$ as the dependent variable, we used iterative regression in SPSS software to build the multiple nonlinear regression model.

In setting the parameters'initial values, C, A1, A2, A3, B1, B2, C1, and C2 were set to 0.001 , and the significance level to $=0.05$. The iteration history and parameter estimation are shown in Table 2. 
Table2. Parameter estimation

\begin{tabular}{ccccc}
\hline & & & \multicolumn{2}{c}{$\mathbf{9 5 \%}$ Confidence Interval } \\
\cline { 4 - 5 } Parameters & Estimation & $\begin{array}{c}\text { Standard } \\
\text { Deviation }\end{array}$ & Lower Limit & Upper Limit \\
\hline C & & & 15.937 & 15.937 \\
A1 & 15.937 & .000 & 8.721 & 8.722 \\
A2 & 8.721 & .000 & 2.669 & 2.737 \\
A3 & 2.703 & .017 & .383 & .384 \\
B1 & .383 & .000 & 70.868 & 70.869 \\
B2 & 70.868 & .000 & -.263 & -.263 \\
C1 & -.263 & .000 & -1.470 & -1.465 \\
C2 & -1.467 & .001 & -.018 & .050 \\
\hline
\end{tabular}

Based on the result of the iterative regression analysis, the CE model of the heavy-duty diesel truck was determined, as shown by Equation (4):

$$
\begin{gathered}
C E=\sum_{j=1}^{n} L_{j} \cdot\left(15.937+8.721 \cdot i_{j}+2.703 \cdot i_{j}^{2}+0.383 \cdot i_{j}^{3}+70.868 \cdot L_{j}^{-0.263}-1.467 \cdot V_{0}+0.016 \cdot V_{0}^{2}\right) \\
i_{j} \in[-0.3 \%,-6 \%] \cup[0.3 \%, 6 \%] \\
L_{j} \in\left[0.2 \mathrm{~km}, L_{\max }\right]
\end{gathered}
$$

In the above equation, $\mathrm{CE}$ has units $10-2 \mathrm{~kg}$, $\mathrm{ij}$ stands for the gradient of the $\mathrm{i}$-th longitudinal segment, $\mathrm{Lj}$ for slope length of the $\mathrm{i}$-th longitudinal segment, Lmax for the maximum slope length in China's expressway design criterion, and V0 for the initial speed when driving on a longitudinal segment.

\section{Results and Discussion}

\section{Establishment of Carbon Emission Database for Expressway Longitudinal Slope}

The existing model is used to simulate the carbon emission data of the vehicle according to the general operating speed, different slope gradient, slope length and different initial velocity.

The data in the database as shown in Figure 6-7, $\mathrm{Z}$ axis is the cumulative carbon emissions $(\mathrm{kg}), \mathrm{i} \in[-6,6 \%], \mathrm{L} \in[0.2 \mathrm{~km}, \mathrm{Lmax}] . \mathrm{Lmax}$ is the maximum slope corresponding to the actual highway slope length $(\mathrm{km})$. 


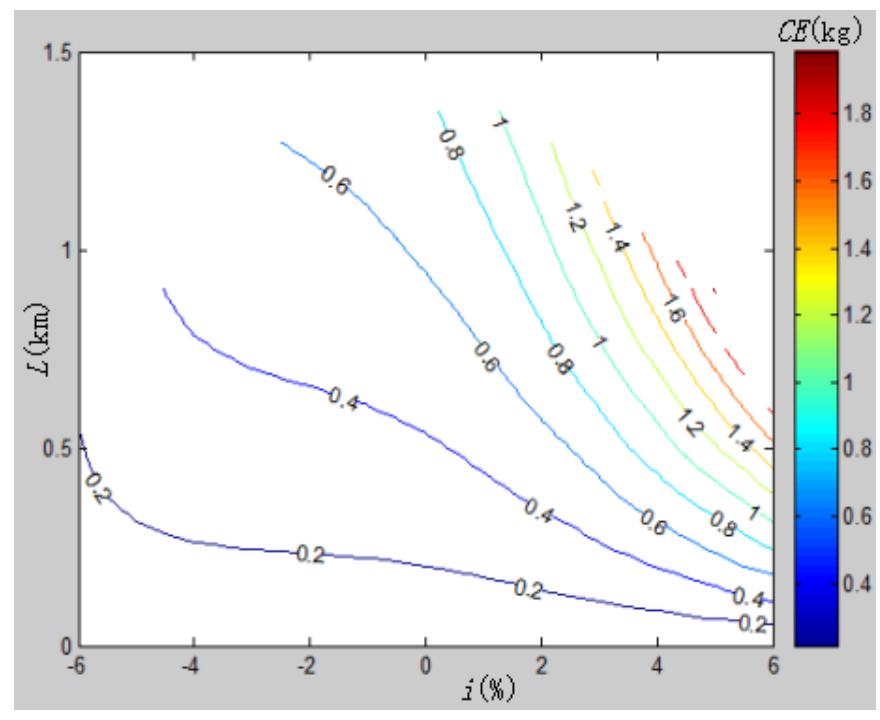

Figure 6. Cumulative carbon emissions at $V 0=70 \mathrm{~km} / \mathrm{h}$

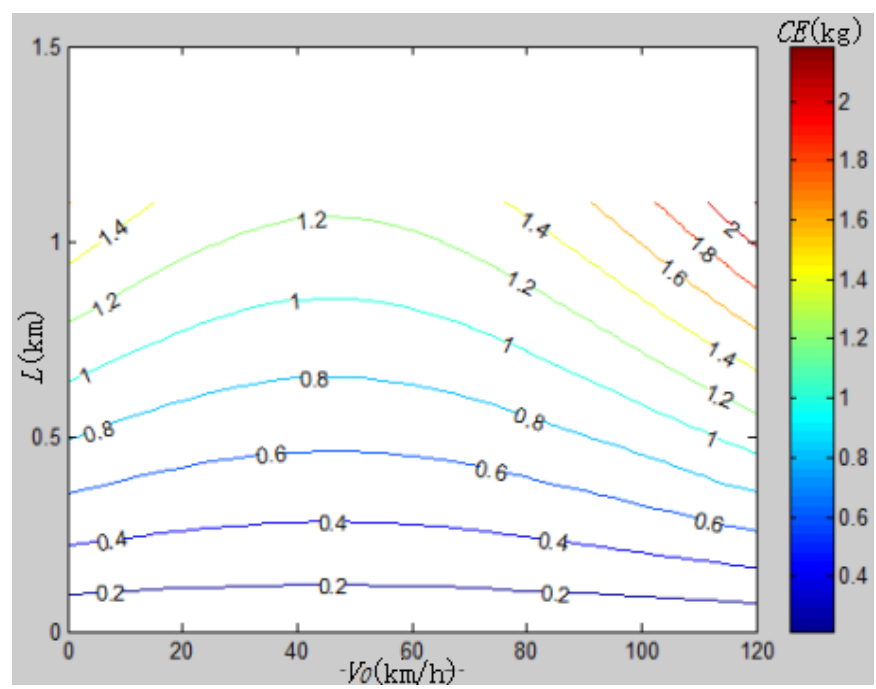

Figure 7. Cumulative carbon emissions at $i=3 \%$

Reasonable index of longitudinal slope considering carbon emission sensitivity

Based on the actual design data, the sensitivity analysis of $\mathrm{i}$ and $\mathrm{L}$ in the established model is carried out. The specific methods are as follows: the conversion rate of $\mathrm{i}$ and $\mathrm{s} \mathrm{L}$ are $10 \%(\mathrm{k}=10 \%)$, calculate the rate of change of carbon emissions.

\section{Gradient sensitivity}

Basic parameters: $\mathrm{L}=0.8 \mathrm{~km}, \mathrm{~V} 0=75 \mathrm{~km} / \mathrm{h}$. On the premise of keeping the above parameters unchanged, $\mathrm{i}$ was changed from $6 \%$ to, $-6 \%$ to $0 \%, \mathrm{k}=10 \%$, and the cumulative carbon emissions were calculated. The relationship is shown in Figure 8. 


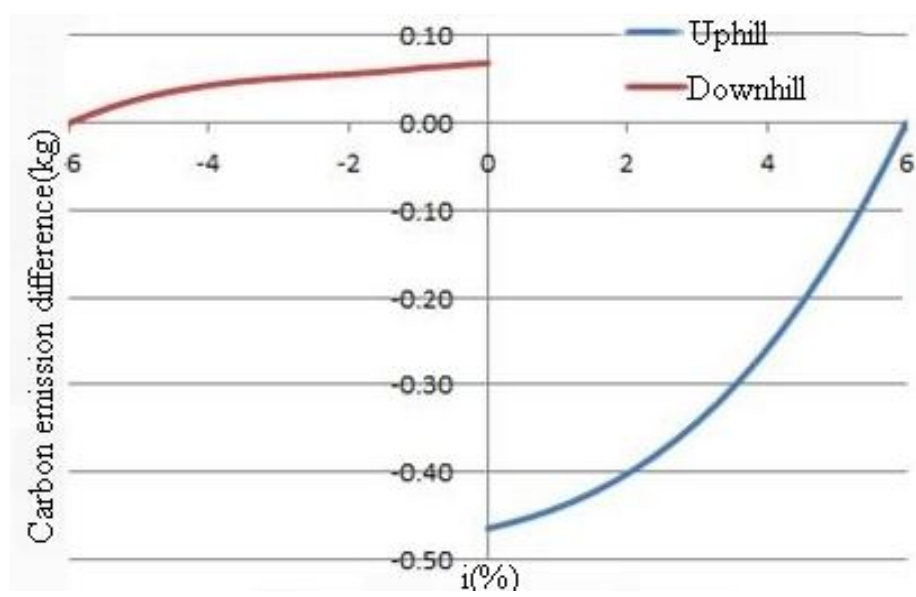

Figure 8. The relationship between cumulative carbon emission value and $i$

Calculated sensitivity value (S), The results are shown in Table 3.

Table 3. Sensitivity value

\begin{tabular}{ccccccc}
\hline & UPhill & \multicolumn{3}{c}{ Downhill } \\
\hline $\mathrm{i}(\%)$ & {$[0,2]$} & {$[2,3]$} & {$[3,6]$} & {$[0,-2]$} & {$[-2,-3]$} & {$[-3,-6]$} \\
$\mathrm{S}$ & 2.671 & 3.151 & 4.550 & -0.693 & -0.665 & -1.603 \\
\hline
\end{tabular}

Based on the result of sensitivity value, the influence of gradient on the cumulative carbon emissions is obvious and higher sensitivity. The sensitivity of uphill slope in [3\% 6\%] is the highest, reaching 4.550. And downhill slope sensitivity is relatively low. The position of the obvious watershed is $\mathrm{i}=2 \% \sim 3 \%$, the results show that the carbon emissions will increase significantly after the longitudinal slope is greater than $3 \%$, highway longitudinal slope should be less than $3 \%$.

\section{Slope length sensitivity}

Basic parameters: $\mathrm{i}= \pm 3 \%, \mathrm{~V} 0=75 \mathrm{~km} / \mathrm{h}$. On the premise of keeping the above parameters unchanged, the $\mathrm{L}$ was changed from $1.1 \mathrm{~km}$ to $0.2 \mathrm{~km}, \mathrm{k}=10 \%$, and the cumulative carbon emissions were calculated. The relationship is shown in Figure 9.

Figure 9 shows that the sensitivity of uphill and downhill slope are 3.297 and 1.495, the effect of uphill slope length on cumulative carbon emissions is more obvious than that of downhill. There is a linear correlation between carbon emissions and slope length. So, the road longitudinal slope length should be limited, especially uphill and long steep slope should be avoided. 


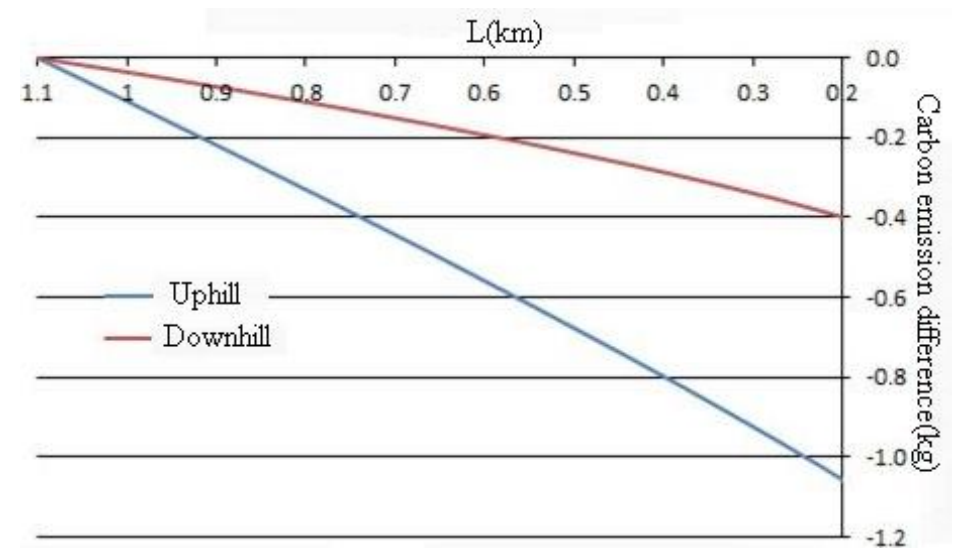

Figure 9. The relationship between cumulative carbon emission value and $L$

\section{Conclusions}

In northern China's coal producing areas, $\mathrm{CE}$ from heavy vehicles operating on overload expressways has a substantial negative impact on the environment and air quality. Therefore, the low-CE design of such expressways is important for environmental governance in the country. In the present study, the CE pattern of an overload expressway was determined, providing theoretical support to environmental design of those expressways.

According to collected data, the 50-t load weight, six-axis Auman heavy duty truck was determined as the dominant vehicle type. A field experiment was conducted to monitor fuel consumption on various longitudinal segments. Then, we used nonlinear iterative regression to study the relationship between $\mathrm{CE}$ and longitudinal geometric elements. In that investigation, an equation calculating $\mathrm{CE}$ on each longitudinal segment based on the gradient, slope length and initial speed was developed.

The existing model is used to simulate the carbon emission data of the vehicle according to the general operating speed, different slope gradient, slope length and different initial velocity. Based on the actual design data, the sensitivity analysis of $i$ and $\mathrm{L}$ in the established model is carried out.

Acknowledgements. This research was supported in part by the Natural Science Foundation of Shaanxi Province, the National Key Research and Development Program of China (No.2016YFC0802208) and the Fundamental Research Funds for the Central Universities (No. 310821151007).

\section{REFERENCES}

[1] Brown, M. A., Southworth, F., Sarzynski, A. (2009): The geography of metropolitan carbon footprints. - Policy and Society 4: 285-304.

[2] Chen, C. H., Huang, C., Jing, Q., Wang, H., Pan, H., Li, L., Zhao, J., Dai, Y., Huang, H., Schipper, L., Streets, G. D. (2007): On-road emission characteristics of heavy-duty diesel vehicles in Shanghai. - Atmospheric Environment 26: 5334-5344. 
[3] De Cauwer, C., Van Mierlo, J., Coosemans, T. (2015): Energy consumption prediction for electric vehicles based on real-world data. - Energies 8: 8573-8593.

[4] Durbin, T. D., Johnson, K., Cocker, III. R. D., Miller, J. W., Maldonado, H., Shah, A., Ensfield, C., Weaver, C., Akard, M., Harvey, N., Symon, J., Lanni, T., Bachalo, D. W., Payne, G., Smallwood, G., Linke, M. (2007): Evaluation and comparison of portable emissions measurement systems and federal reference methods for emissions from a back-up generator and a diesel truck operated on a chassis dynamometer. - Environmental Science \& Technology 17: 6199-6204.

[5] Feng, X., Wang, T. L., Zhao, Q. (2013): The application of the IVE model for establishing the vehicle emission inventory in the urban areas of Chongqing. - Application Mechanical Materials 361: 854-859.

[6] Frey, H. C., Rouphail, N. M., Zhai, H. B. (2008): Link-based emission factors for heavy-duty diesel trucks based on real-world data. - Transportation Research Record 2058: 23-32.

[7] Huang, C., Chen, C. H., Lou, D. M. (2010): Real world fuel consumption and emissions simulation and its application for heavy duty diesel vehicles. - Acta Scientiae Circumstantiae 12: 2369-2376.

[8] Imhof, K., Oesch, F., Nordanlycke, I. (1996): Modelling of tap-changer transformers in an energy management system. - IEEE Transactions on Power System 11: 428-434.

[9] Jiao, S. J., Li, L. F., Li, Y. W. (2014): Analysis on influence factors for the whole life-cycle carbon emissions of highway and carbon accounting. - Advanced Materials Research 869: 826-831.

[10] Joumard, R., Andre, M., Tassel, P. (2000): Influence of driving cycles on unit emissions from passenger cars. - Atmospheric Environment 34: 4621-4628.

[11] Kang, S., Min, K. (2016): Dynamic simulation of a fuel cell hybrid vehicle during the federal test procedure-75 driving cycle. - Application energy 161: 181-196.

[12] Lai, J. X., Wang, K. Y., Liu, C. (2015): Safety computational assessment of segments repairment employing BICS based on load-structure finite element model. - Journal of Information and Computational Science 12: 3961-3969.

[13] Liu, J., Dong J. J., Shi, X. P. (2011): Research for NOx emission of Nanjing vehicle based on IVE model. - Application Mechanical Materials 99: 1341-1345.

[14] Morrow, R. W., Gallagher, S. K., Collantes, G., Lee, H. (2010): Analysis of policies to reduce oil consumption and greenhouse-gas emissions from the US transportation sector. Energy Policy 3: 1305-1320.

[15] National Bureau of Statistics in People's Republic of China. (2014): China Energy Statistical Yearbook 2014. China Statistics Press: Beijing, China, 2015: 203-207.

[16] Oh, C., Cha, G. (2015): Impact of fuel, injection type and after-treatment system on particulate emissions of light-duty vehicles using different fuels on FTP-75 and HWFET test cycles. - International Journal of Automotive Technology 16: 895-901.

[17] Ortenzi, F., Chiesa, M., Scarcelli, R. (2008): Experimental tests of blends of hydrogen and natural gas in light-duty vehicles. - International Journal of Hydrogen Energy 33: 3225-3229.

[18] Peng, B., Cai, C. L., Yin, G. K., Li, W., Zhan Y. (2015): Evaluation system for CO2 emission of hot asphalt mixture. - Journal of Traffic and Transportation Engineering: English Edition 2: 116-124.

[19] Qin, K. J., Gao, J. H., Gao, J. D.. (2009): Integration and validation of an on-board emission measurement system for heavy-duty vehicles. - Automotive Engineering 11: $1081-1085$.

[20] Rakha, H., Ahn, K., Trani, A. (2004): Development of VT-Micro model for estimating hot stabilized light duty vehicle and truck emissions. - Transportation Research Part D 9: 49-74. 
[21] Rogers, C. D., Thomas, A. M., Jefferson, L. (2009): Carbon dioxide emissions due to highway subgrade improvements. - Transportation Research Record 2104: 80-87.

[22] Shah, I. H., Zeeshan, M. (2016): Estimation of light duty vehicle emissions in Islamabad and climate co-benefits of improved emission standards implementation. - Atmospheric Environment 127: 236-243.

[23] Shah, S. D., Cocker, D. R., Miller, J. W. Norbeck, M. J. (2004): Emission rates of particulate matter and elemental and organic carbon from in-use diesel engines. Environmental Science \& Technology 38: 2544-2550.

[24] Trainer, T. (2010): A critical discussion of the stern and IPCC analyses of carbon emission mitigation possibilities and costs. - Energy and Environment 21: 49-73.

[25] Yafune, A., Narukawa, M., Ishiguro, M. (2005): A note on sample size determination for Akaike Information Criterion (AIC) approach to clinical data analysis. - Communications in Statistics-Theory and Methods 34: 2331-2343.

[26] Yuan, C. W., Zhang, Q., Rui, X. L. (2016): Spatiotemporal evolution and difference of transport carbon emissions in China . - Acta Scientiae Circumstantiae 12: 4551-4562. 